\title{
THỬ NGHIỆM ĐỒNG HÓA SỐ LIỆU BẰNG WRF 4D-Var TRONG DỬ BÁO MƯA Ở KHU VỰC NAM BỘ
}

\author{
Vũ Văn Thăng1, Trần Duy Thức ${ }^{1}$, Nguyễn Quang Trung1
}

Tóm tắt: Đồng hóa số liệu biến phân bốn chiều (4D-Var) là kỹ thuật đồng hóa tiên tiến được ứng dụng ở nhiều nơi trên thế giới, nhờ ưu điểm tối ưu trường phân tích không nhũng về mặt thống kê toán hoc mà còn phù hợp về mặt động lục. Nghiên cưu này, lần đầu tiên, giới thiệu việc thử nghiệm áp dụng phưong pháp 4D-Var thông qua mô hình WRF (Weather Research and Forecasting model) trong dụ báo mura ở Việt Nam, cu thể là khu vục Nam Bộ. Các thí nghiệm đồng hóa số liệu mua tụ động và số liệu radar trong dụ báo đọt mua ngày 25 và 26/11/2018 được tiến hành. Bên cạnh đó, hai thi nghiệm về độ nhạy với quan trắc đơn cunng được thực hiện, với sụ thay đổi luợng mưa đồng hóa tại một điểm trạm. Kết quả cho thấy phuong pháp 4D-Var đã điều chinh các biến co bản của truờng ban đầu (ví dụ nhu nhiệt độ, độ ẩm) dù chi có sụ thay đổi nhỏ của lương mura được đồng hóa. Mô phỏng thực tế cho thấy, so với trương hơp không đồng hóa, phưong pháp đồng hóa 4D-Var có tác động cải thiện dụ báo ở cả hạn dụ báo $12 \mathrm{~h}$ và 24h. Các phuoong án đồng hóa nhìn chung cho sai số nhỏ hơn so với truờng hơp không đồng hóa, ở các nguõng mura nhỏ duoói $30 \mathrm{~mm}$ và mura lớn trên $70 \mathrm{~mm}$. Bên cạnh đó, nghiên cứu cũng chỉ ra yêu cầu về mặt tài nguyên tính toán của phuong pháp 4D-Var lớn hơn đáng kể so với phưong pháp biến phân ba chiều.

Từ khóa: WRFDA, 4DVar, Đồng hóa số liệu, Radar, Mura lớn, Khu vực Nam Bộ.

Ban Biên tập nhận bài: 11/12/2019 Ngày phản biện xong: 12/12/2019 Ngày đăng bài:20/12/2019

\section{Mở đầu}

Đồng hóa số liệu biến phân bốn chiều (FourDimensional Variational hay 4 D-Var) là phương pháp đồng hóa tiên tiến trong đó trường ban đầu được điều chỉnh, gần hơn với trường quan trắc, thông qua sự điều chỉnh tối ưu cả về mặt vật lý và toán học của mô hình, trong cửa sổ đồng hóa [6]. Phương pháp này, như được xây dựng trong mô-đun đồng hóa của mô hình WRF (Weather Research and Forecasting model data assimilation system - WRFDA), dựa trên các chu trình lặp để cực tiểu hóa hàm giá [1]. Với một tập hợp các vòng lặp lồng nhau, lặp lại tiến và lùi theo thời gian, trường phân tích được điều chỉnh đồng thời theo số liệu quan trắc và sự phù hợp với các biến khác của mô hình [3].

So với phương pháp 3D-Var, phương pháp 4D-Var xử lý số liệu trên cả chiều thời gian giúp trường phân tích không những tối ưu theo nghĩa thống kê mà còn phù hợp về mặt động lực. Từ đó, trường nền có thể thay đổi theo thời gian và phù hợp hơn với từng hình thế thời tiết. Hơn thế nữa, 4D-Var có thể đồng hóa được nhiều loại số liệu mà 3D-Var không đồng hóa được (ví dụ lượng mưa) [1]. Tuy nhiên, nhược điểm của 4DVar là khối lượng tính toán lớn, đòi hỏi hệ thống máy tính phải đủ mạnh.

Sau khi kỹ thuật 4D-Var được áp dụng thành công cho mô hình toàn cầu tại Trung tâm Dự báo hạn vừa Châu Âu (ECMWF), các hệ thống 4DVar khác nhau đã được phát triển ở nhiều trung tâm dự báo trên thế giới như Cơ quan Khí tượng của Nhật (JMA), Cơ quan Khí tượng của Pháp (MétéoFrance) $[2,13]$. Riêng đối với bài toán dự báo mưa, đã có nhiều nghiên cứu thử nghiệm phương pháp 4D-Var. Mazzarella Vincenzo ccs., (2017) đã so sánh hai phương pháp 3D-Var và 4D-Var, trong mô phỏng một trường hợp mưa

IViện Khoa học Khi tượng Thủy văn và Biến đổi khí hậu

Email:vvthang26@gmail.com 
lớn ở miền trung nước Ý, thông qua việc đồng hóa độ phản hồi và tốc độ gió xuyên tâm từ radar. Với chín thí nghiệm được thực hiện, kết quả cho thấy phương pháp 4D-Var giúp cải thiện dự báo mưa định lượng tốt hơn so với 3D-Var, đặc biệt ở các ngưỡng lượng mưa lớn [11].

Pan Xiaoduo cs., (2017) đã sử dụng WRF 4D-Var để đồng hóa sản phẩm mưa từ vệ tinh TRMM 3B42 và FY-2D cho lưu vực sông Heihe (tây bắc Trung Quốc), nơi có địa hình rất phức tạp. Kết quả cho thấy việc đồng hóa lượng mưa cải thiện các trường độ ẩm và nhiệt độ trong WRF tại trường ban đầu, từ đó cải thiện dự báo lượng mưa và giảm thời gian spinup [12].

Lopez và Bauer (2007) đã sử dụng phương pháp “1D + 4D-Var" để đồng hóa lượng mưa tại ECMWF. Đầu tiên, thông qua cách tiếp cận 1DVar, nhiệt độ và độ ẩm được ước lượng từ tốc độ mưa bề mặt. Sau đó, tổng lượng hơi nước trong cột khí quyển, thu được từ bước thứ nhất, được đồng hóa trong 4D-Var. Ở đây, thông tin về lượng mưa đã được chuyển đổi thành thông tin độ ẩm trước khi được sử dụng trong 4D-Var [910].

Junmei Ban ccs., (2017) đã đồng hóa trực tiếp dữ liệu lượng mưa bằng phương pháp 4D-Var. Các thí nghiệm trong một tuần đã được thực hiện nhằm kiểm tra ảnh hưởng của đồng hóa lượng mưa đến các mô phỏng. Kết quả đánh giá với một quan trắc đơn cho thấy, đồng hóa lượng mưa có tác động tích cực đến các trường mô hình, đặc biệt là độ ẩm ở mực thấp. Đối với tác động đến dự báo lượng mưa, kết quả chỉ ra rằng sự đồng hóa làm giảm thời gian spinup hiệu quả và tạo ra lượng mưa dự báo mô hình gần hơn với các quan trắc thông qua sự thay đổi nhiệt độ, độ ẩm và gió và tác động từ sự đồng hóa lượng mưa tồn tại trung bình đến khoảng ba giờ sau khi mô hình khởi chạy [5] .

Ở Việt Nam, trong khi các nghiên cứu với phương pháp 3D-Var đã được quan tâm và áp dụng thì chưa có ứng dụng nào đối với phương pháp 4D-Var [7-8]. Huỳnh Thị Hồng Ngự và La Thị Cang (2008) đã giới thiệu về 4D-Var và chỉ dừng lại ở những biện luận về khả năng áp dụng 4D-Var trong dự báo thời tiết bằng các mô hình số trị và hướng phát triển trong tương lai của kỹ thuật này ở Việt Nam [4]. Từ đó, nghiên cứu này sẽ lần đầu tiên thử nghiệm đồng hóa số liệu bằng phương pháp 4D-Var sử dụng mô hình WRF. Mục 2 sẽ làm rõ về phương pháp nghiên cứu và các nguồn số liệu. Mục 3 sẽ trình bày các kết quả với hai loại thí nghiệm, về độ nhạy với quan trắc đơn và dự báo thử nghiệm một đợt mưa thực tế. Một số kết luận sẽ được đúc kết trong Mục 4.

\section{Phương pháp nghiên cứu và nguồn số liệu}

\subsection{So' lươc về WRF 4D-Var}

Về mặt toán học, mục tiêu của WRF 4D-Var là tìm ra ước tính tối ưu của trạng thái khí quyển thực tại thời điểm phân tích, bằng cách tối thiểu hóa hàm giá:

$$
\mathrm{J}=\mathrm{J}_{\mathrm{b}}+\mathrm{J}_{\mathrm{o}}+\mathrm{J}_{\mathrm{c}}
$$

Trong đó, $\mathrm{J}_{\mathrm{b}}$ là hàm giá của trạng thái nền của mô hình, $\mathrm{J}_{\mathrm{o}}$ là hàm giá của trường quan trắc và $\mathrm{J}_{\mathrm{c}}$ là thành phần cân bằng trong hàm giá [3]. Hình 1 minh họa về phương thức hoạt động của 4DVar trong một cửa số đồng hóa. Trong đó, Obs là số liệu quan trắc, $X_{a}$ là trường phân tích (sau đồng hóa), $X_{b}$ là trạng thái mô hình ban đầu. $J_{0}$ thể hiện cho sự điều chỉnh trong cửa sổ đồng hóa, $\mathrm{J}_{\mathrm{b}}$ là đại diện cho sự điều chỉnh ở trạng thái ban đầu. Đường màu xanh là dự báo ban đầu của mô hình và đường màu đỏ là dự báo của mô hình đã qua điều chỉnh với số liệu quan trắc trong cửa sổ đồng hóa $12 \mathrm{~h}$.

Đối với một tham số $\mathrm{X}_{\mathrm{b}}$ ban đầu, tất cả các quan trắc có trong cửa sổ đồng hóa (ở đây là $12 \mathrm{~h}$ ) được so sánh với các dự báo hạn ngắn từ trường phân tích trước đó. Trạng thái mô hình $\mathrm{X}_{\mathrm{b}}$ tại thời điểm ban đầu được điều chỉnh sao cho có được mối liên hệ tốt nhất với số liệu quan trắc bằng việc cực tiểu hóa hàm giá. Kết quả là mô hình được chạy tích phân tiến và lùi theo thời gian, trích xuất thông tin từ tất cả các điểm quan trắc và lặp lại một số lần, nhằm cực tiểu hàm giá và thay đổi trạng thái mô hình phù hợp với những quan trắc đó [3]. 


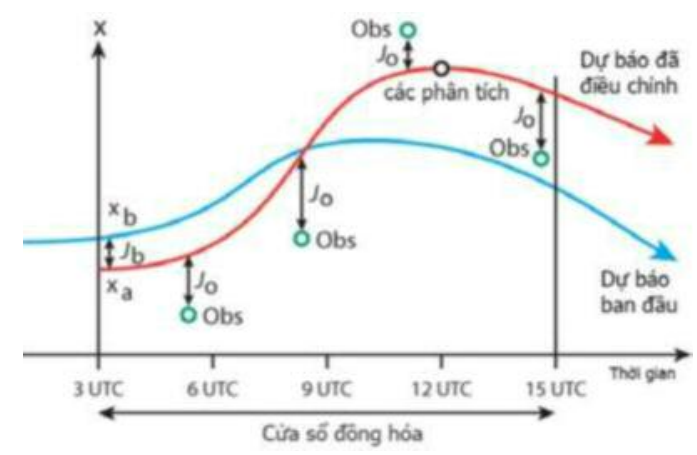

Hình 1. Mô tả cửa sổ đồng hóa của WRF 4D-Var, theo [3]

\subsection{Cấu hình mô hình WRF}

Mô hình WRF cũng các mô-đun WRF-DA và WRF-PLUS phiên bản V3.9.1 được sử dụng trong nghiên cứu này [14]. Cấu hình các thí nghiệm được thực hiện với ba lưới lồng, tương tác hai chiều, có độ phân giải tương ứng là: 54 $\mathrm{km}, 18 \mathrm{~km}$ và $6 \mathrm{~km}$ (Hình 2$)$. Số điểm lưới của ba miền tính $1,2,3$ lần lượt là $100 \times 65,151 \times 91$, $157 \times 109$ điểm lưới, với tọa độ tâm tại $10,66^{\circ} \mathrm{N}$; $106,73^{\circ} \mathrm{E}$. Số mực thẳng đứng là 38 và bước thời gian tích phân là 120 s. Bảng 1 trình bày các sơ đồ tham số hóa vật lý của mô hình WRF được sử dụng trong nghiên cứu này. Đối với miền tính trong cùng (độ phân giải $6 \mathrm{~km}$ ), không sử dụng sơ đồ tham số hóa đối lưu. Trong cấu hình của WRF-DA, ma trận sai số trường nền CV7 được sử dụng $[3,14]$. Trường nền CV7 sử dụng các biến điều khiển chính là gió kinh - vĩ hướng, nhiệt độ, độ ẩm tương đối giả (pseudo) và khí áp bề mặt. Ma trận sai số được tính toán riêng cho từng miền tính bằng phương pháp $\mathrm{NMC}$, sử

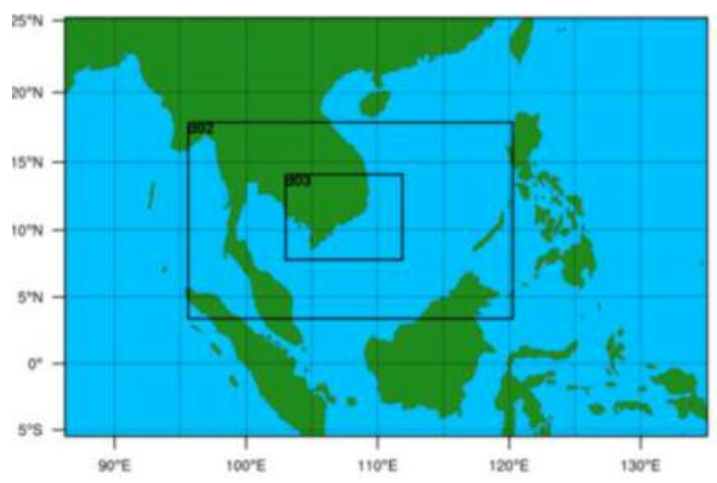

Hình 2. Các miền tính của mô hình WRF dụng sự khác biệt giữa dự báo $24 \mathrm{~h}$ và $12 \mathrm{~h}$. Ma trận trường nền thường được tính toán trong một tháng, từ $01 / 10 / 2018$ đến $31 / 10 / 2018$.

\subsection{Thiết kế thí nghiệm}

Hai loạt thí nghiệm được thực hiện trong nghiên cứu này bao gồm:

\subsection{1 Đánh giá độ nhạy với quan trắc đơn}

Một bước cơ bản để kiểm nghiệm sự ảnh hưởng của đồng hóa 4D-Var đến trường ban đầu là thí nghiệm với quan trắc đơn. Tại điểm có tọa độ $11.17^{\circ} \mathrm{N} ; 106.49^{\circ} \mathrm{E}$, giá trị lượng mưa ban đầu khoảng 2 mm (Hình 3). Để thử nghiệm độ nhạy với quan trắc đơn (single observation test), hai thí nghiệm được thực hiện, bao gồm:

- TN1: tăng giá trị lượng mưa tại điểm này lên 40mm (tăng 15mm)

- TN2: giảm giá trị lượng mưa tại điểm này xuống $15 \mathrm{~mm}$ (giảm 10mm)

Trong hai thử nghiệm này, cửa sổ đồng hóa được đặt một phía, từ 0 đến $1 \mathrm{~h}$, và mô hình được tích phân từ thời điểm $12 Z$ ngày $25 / 11 / 2018$.

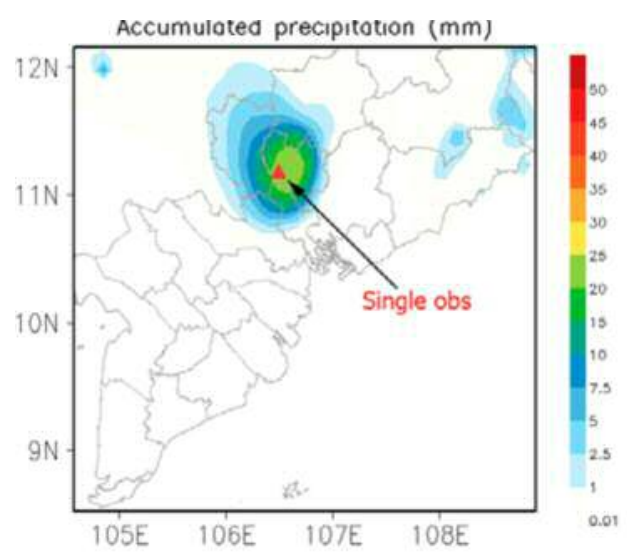

Hình 3. Điểm quan trắc được thay đổi giá trị luợng muxa trong thi nghiệm độ nhạy với quan trắc đơn 
2.3.2 Thử nghiệm dụ báo đơt mưa 25$26 / 11 / 2018$

Đợt mưa trong hai ngày 25 và $26 / 11 / 2018$ được lựa chọn để tiến hành thử nghiệm đồng hóa dữ liệu lượng mưa và độ phản hồi radar. Bảng 2 mô tả sơ lược về 05 thí nghiệm được tiến hành. Đây là đợt mưa lớn gây nên bởi bão Usagi, một cơn bão mạnh, đổ bộ trực tiếp vào Cần Giờ (TP. Hồ Chí Minh) vào ngày 25/11/2018.

Trong thí nghiệm chạy 3D-Var, do số liệu radar thay đổi rất nhanh theo thời gian, cửa sổ đồng hóa được đặt là 15 phút. Tổng số lượng điểm quan trắc có độ phản hồi và gió xuyên tâm được đồng hóa là 25.018. Trong khi ở trường hợp chạy 4D-Var, với cửa số đồng hóa 3 tiếng, tổng số lượng quan trắc đưa vào là 72.370 (tăng 2,8 lần).

Đối với số liệu đo mưa tự động, WRF-4DVar có khả năng đồng hóa lượng mưa tích lũy từng giờ, 3h, $6 \mathrm{~h}$ hoặc lâu hơn. Trong nghiên cứu này, số liệu mưa tích lũy $3 \mathrm{~h}$ và $6 \mathrm{~h}$ của 219 trạm quan trắc mưa được sử dụng để đồng hóa. Một số nghiên cứu cho thấy đồng hóa lượng mưa tích lũy $6 \mathrm{~h}$ cho kết quả tốt hơn so với việc đồng hóa số liệu từng giờ [6]. Mô hình WRF được khởi chạy vào thời điểm $12 \mathrm{Z}$ của ngày 24 và $25 / 11 / 2018$ để dự báo cho hai ngày 25 và $26 / 11 / 2018$.

\section{Bảng 1. So đồ vật lý của mô hình WRF trong các thí nghiệm}

\begin{tabular}{lc}
\hline \multicolumn{1}{c}{ Loại so đồ } & Tên so đồ được sử dụng \\
\hline Lớp biên hành tinh & Yonsei University (YSU) \\
Tham số hóa đối lưu & Betts-Miller-Janjic (BMJ) \\
Sơ đồ vi vật lý mây & Sơ đồ Thompson \\
Bức xạ sóng ngắn & Sơ đồ Dudhia \\
Bức xạ sóng dài & Sơ đồ RRTMG \\
Sơ đồ đất & Mô hình đất Noah \\
\hline
\end{tabular}

\subsection{Nguồn số liệu và chỉ số đánh giá}

Số liệu điều kiện ban đầu và điều kiện biên để chạy mô hình WRF được khai thác từ số liệu dự báo của mô hình toàn cầu GFS (Global Forecast System) của Trung tâm Quốc Gia Dự báo Môi trường, Mỹ ở độ phân giải $0.5^{\circ}$ x $0.5^{\circ}$. Số liệu độ phản hồi và tốc độ gió xuyên tâm của Radar Nhà Bè cũng được lấy trong thời gian tương ứng, với bán kính $120 \mathrm{~km}$ và 5-8 góc nâng. Trước khi đồng hóa cho WRF, số liệu radar đã được lọc nhiễu (Hình 4) [15]. Số liệu mưa tích lũy theo giờ dùng để đồng hóa bao gồm số liệu 3h và $6 \mathrm{~h}$ tại 219 trạm đo mưa tự động ở khu vực Nam Bộ, trong hai ngày 25 và 26/11/2018 (Hình 5).

Để đánh giá các thử nghiệm, bên cạnh so sánh trực quan trên bản đồ, hai chỉ số FBI (BS hay FBI - Bias score) và CSI (Critical Success Index hay TS) sẽ được sử dụng. Các chỉ số được tính từ bảng ngẫu nhiên 2 chiều (contingency table), cho phép so sánh khách quan giữa lượng mưa quan trắc và dự báo với các ngưỡng: 1, 10, 20, 30, 40, 50, 60, 70, 80, 90, 100, 110, 120, 130, 140, 150, $160,170,180,190$ và $200 \mathrm{~mm}$. Giá trị FBI biến đổi trong khoảng $[0,+\infty)$. FBI càng nhỏ hơn 1 , kết quả dự báo của mô hình càng bỏ sót nhiều trường hợp quan trắc. $\mathrm{FBI}$ càng lớn hơn 1 , các dự báo khống càng nhiều. CSI phản ánh mối quan hệ giữa số lần mô hình cho kết quả hiện tượng có xuất hiện và số lần quan trắc được hiện tượng có xuất hiện. Phạm vi biến thiên của CSI từ 0 đến 1 . CSI bằng 0 nghĩa là mô hình không có kỹ năng, CSI bằng 1 cho thấy mô hình hoàn hảo. Với việc đánh giá cho hai ngày mưa lớn và 219 trạm, dung lượng mẫu sẽ là 438. Do đó, các chỉ số tính toán ở đây mang ý nghĩa về mặt không gian hơn là mặt thời gian. 


\section{BÀI BÁO KHOA HỌC}
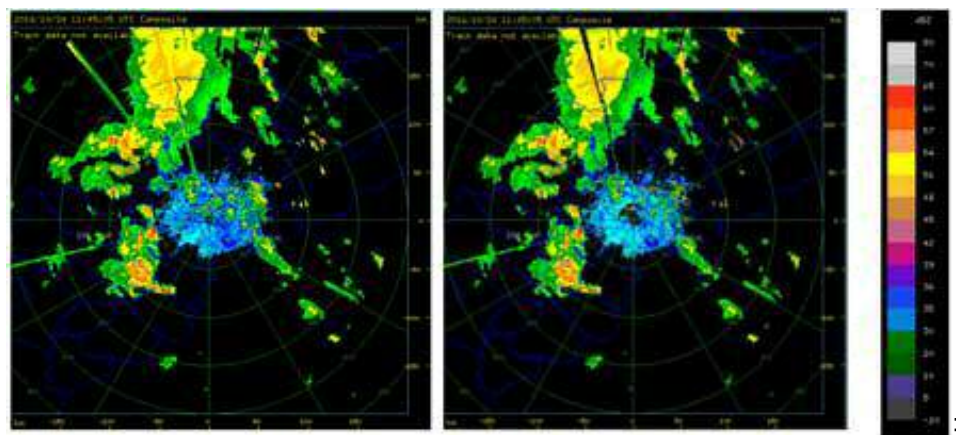

Hình 4. Minh họa về độ phản hồi của Radar Nhà Bè trước (bên phải) và sau (bên trái) loc nhiêu, theo [15]

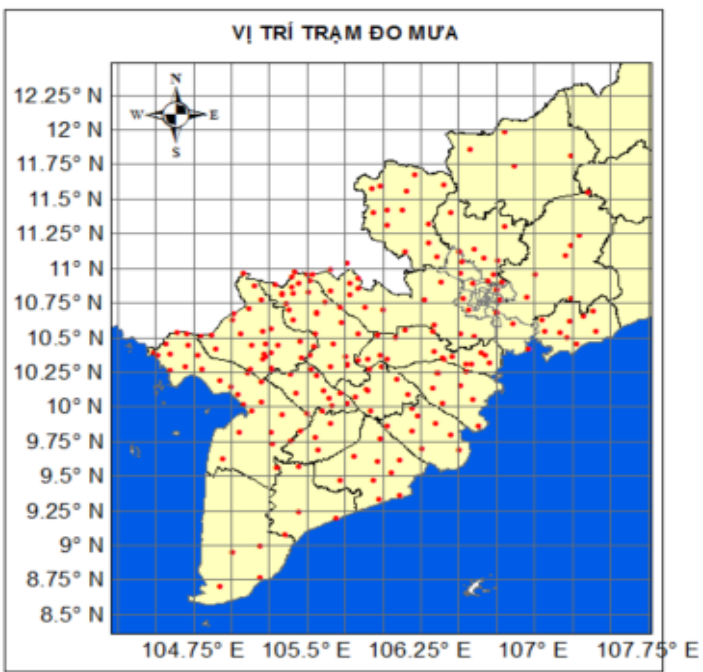

Hình 5. Vị trí các điểm trạm (chấm đỏ) được khai thác số liệu để đồng hóa

Bảng 2. Các truòng hợp thư nghiệm cho đọt mura ngày 25-26/11/2018

\begin{tabular}{lc}
\hline \multicolumn{1}{c}{ Tên thí nghiệm } & Mô tả sơ lược \\
\hline CTL & Không đồng hóa số liệu \\
4D_RAIN6h & 4D-Var, đồng hóa số liệu mưa, c'â sổ 6 giờ \\
4D_RADAR & 4D-Var, đồng hóa số liệu radar, c'a a sổ 3 giờ \\
4D_RAINRADAR & 4D-Var, đồng hóa số liệu mưa vvTradar, c'a a sổ 3 giờ \\
3D_RADAR & 3D-Var, đồng hóa số liệu radar \\
\hline
\end{tabular}

\subsection{Thời gian mô phỏng}

Một điểm lưu ý khi áp dụng phương pháp đồng hóa 4D-Var là việc đòi hỏi tài nguyên tính toán lớn. Việc đánh giá thời gian mô phỏng, so sánh giữa phương pháp 3D-Var và 4D-Var, với các cửa sổ đồng hóa khác nhau, sẽ được trình bày trong mục này (Hình 6). Thời gian mô phỏng không chỉ phụ thuộc vào cửa sổ đồng hóa (3h hay $6 \mathrm{~h}$ ) mà còn phụ thuộc vào số lần lặp để cực tiểu hóa.

Cấu hình của hệ thống máy dùng để thực hiện các thí nghiệm này như sau: (1) một máy chủ Dell PowerEdge R720, 02 Intel Xeon E5-2690 2.9GHz, 8Core; 192GB RAM; 2 x 146GB 15k SAS 2.5 và (2) 16 máy trạm tính toán Dell PowerEdge M620, 02 Intel Xeon E5-2680 2.7GHz, 8Corre; 32GB RAM; 2 x 146GB 15k SAS 2.5. Tất cả các máy sử dụng hệ điều hành CentOS.

Hình 6 cho thấy tốc độ mô phỏng trung bình khi dùng $3 \mathrm{D}-$ Var chỉ mất vài phút. Trong khi đó, khi sử dụng 4D-Var phải mất gần 8 tiếng mô phỏng trên 1 nodes tính toán (16 tiến trình). Kết 
quả này cho thấy cần cân nhắc về tài nguyên tính toán trước khi áp dụng 4D-Var (đặc biệt là trong dự báo nghiệp vụ).

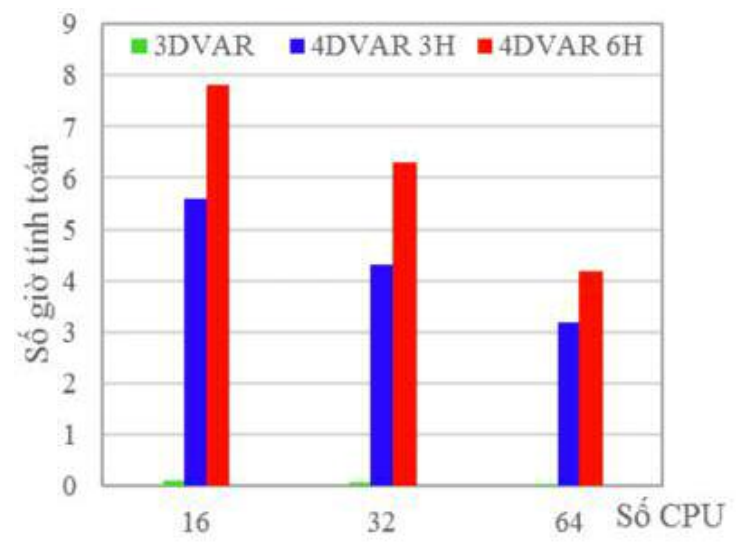

Hình 6. So sánh thời gian mô phỏng của WRF khi đồng hóa 4D-Var (cưa sổ đồng hóa 3h,6h) và $3 D$-Var

\section{Kết quả và thảo luận}

\section{1 Độ nhạy với quan trắc đơn}

Hình 7 biểu diễn hiệu mặt cắt thẳng đứng của trường phân tích trừ đi trường ban đầu (first guess) của biến nhiệt độ và độ ẩm trong thí nghiệm TN1. Có thể thấy, khi lượng mưa đồng hóa vào WRF được giả định tăng lên, trường ban đầu có sự điều chỉnh bằng sự tăng nhiệt độ, ở vị trí quan trắc đơn, từ mực $900 \mathrm{hPa}$ đến $600 \mathrm{hPa}$, tương ứng với ẩn nhiệt được giải phóng trong quá trình ngưng tụ. Trong khi đó, độ ẩm tăng lên ở trên mực 400 hPa (Hình 7.b). Xu hướng hội tụ của trường gió ở mực thấp $~ 850 \mathrm{hPa}$ (Hình $8 . \mathrm{a}$ ) và xu thế phân kỳ ở mực cao $300 \mathrm{hPa}$ (Hình 8.b) gần vị trí điểm quan trắc đã chỉ ra sự tăng cường của đối lưu. Mặc dù các thay đổi là rất nhỏ (chỉ khoảng $0.001-0.003 \mathrm{oC}$ với nhiệt độ và $0.001-0.015 \mathrm{~m} / \mathrm{s}$ với trường gió), nhưng có thể thấy, khi đồng hóa một lượng mưa lớn hơn (so với dự báo), mô hình sẽ tự điều chỉnh các biến để tạo ra trường ban đầu với những điều kiện thuận lợi để hình thành mưa. Từ đó, nếu đồng hóa một số lượng điểm quan trắc nhất định, sẽ tạo ra sự thay đổi đáng kể ở trường ban đầu. Mặc dù chỉ có số liệu lượng mưa được đồng hóa, phương pháp 4D-Var có thể lan truyền thông tin quan trắc đơn theo không gian và có thể điều chỉnh nhiệt độ, độ ẩm và trường gió, dựa trên các mối quan hệ ràng buộc trong mô hình.
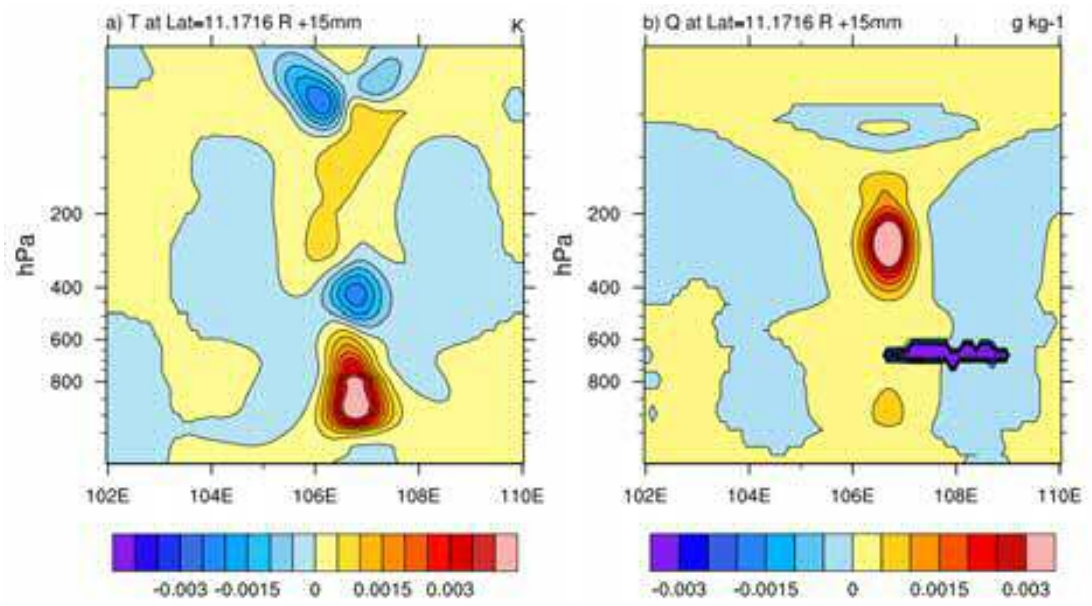

Hình 7. Hiệu mặt cắt thẳng đưng của truòng phân tích trù đi trưòng ban đầu của biến nhiệt độ (a) và độ ẩm (b) trong thí nghiệm TN1

Hình 9 biểu diễn hiệu mặt cắt thẳng đứng tương tự hình 7 nhưng cho thí nghiệm TN2, khi giá trị lượng mưa tại điểm quan trắc bị giảm đi. Có thể thấy, nhiệt độ ở cả cột khí quyển bị giảm đi so với ban đầu, đồng thời trường độ ẩm cũng có xu hướng thấp hơn (Hình 9.b). Ở mực thấp $\sim 850$ hPa (Hình 10.a) cho thấy gió có xu hướng phân kỳ, trong khi gió ở mực trên cao 300 hPa (Hình 10.b) có sự hội tụ yếu, cho thấy sự suy giảm đối lưu. Kết quả này có xu thế ngược lại so với TN1. Có thể thấy, khi đồng hóa một lượng mưa nhỏ hơn so với giá trị dự báo, mô hình sẽ điều chỉnh để tạo ra trường ban đầu với các điều kiện thuận lợi cho việc hạn chế tạo ra mưa. 


\section{BÀI BÁO KHOA HỌC}
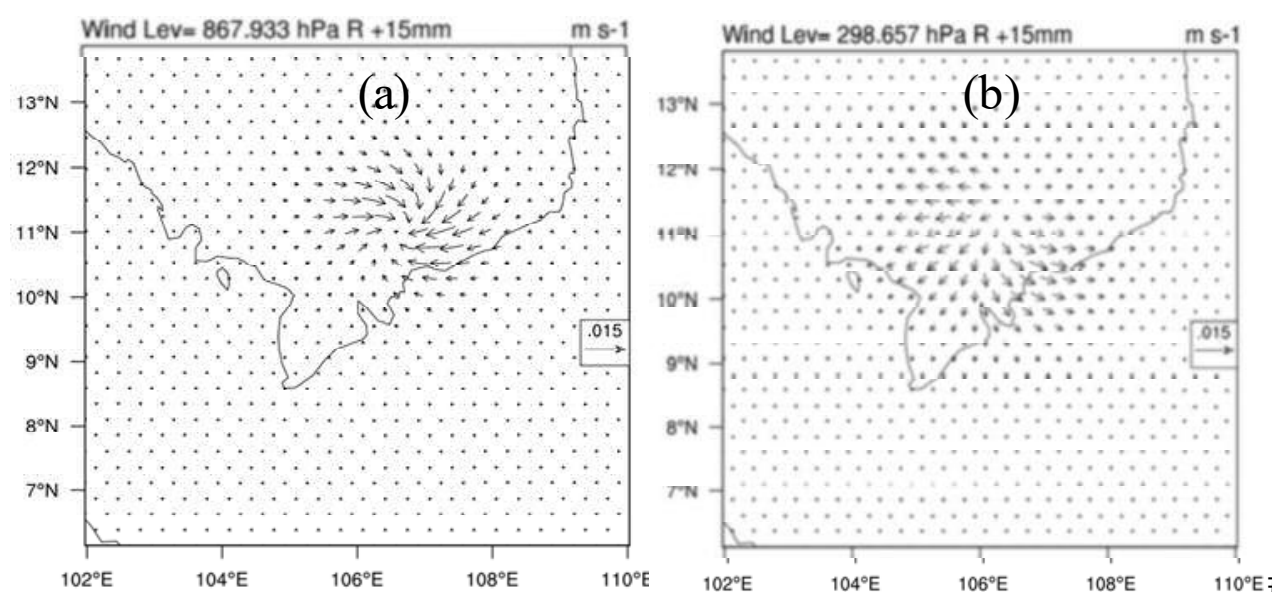

Hình 8. Hiệu truoòng gió của truờng phân tích trù̀ đi truòng ban đầu ở mục 850 hPa (a) và mục $\sim 300$ hPa (b) trong thi nghiệm TN1
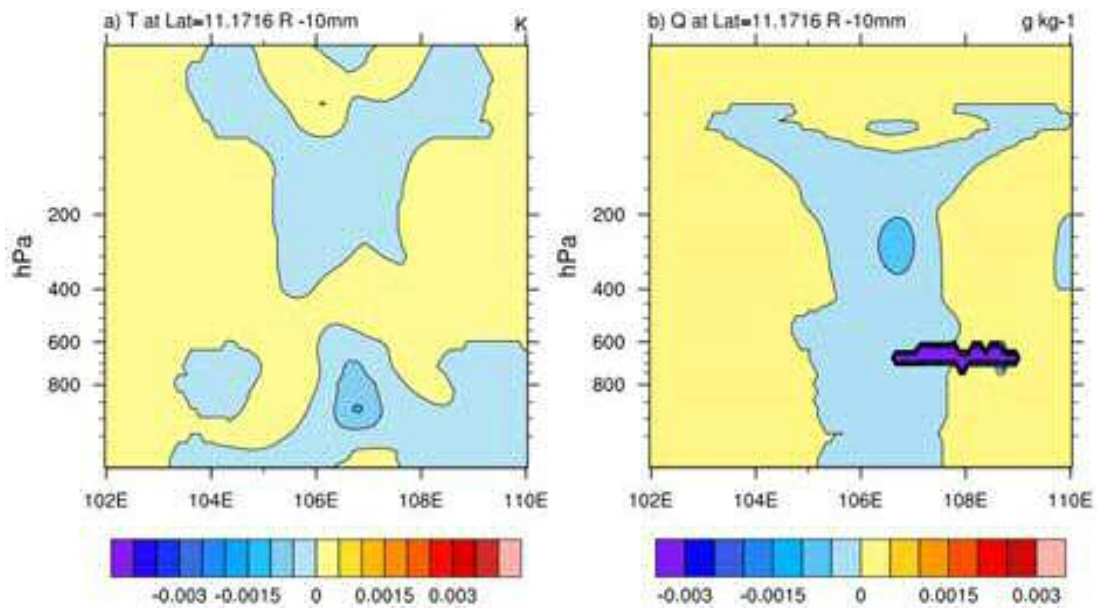

Hình 9. Hiệu mặt cắt thẳng đứng của truòng phân tích trù đi trương ban đầu của biến nhiệt độ (a) và độ ẩm (b) trong thí nghiệm TN2
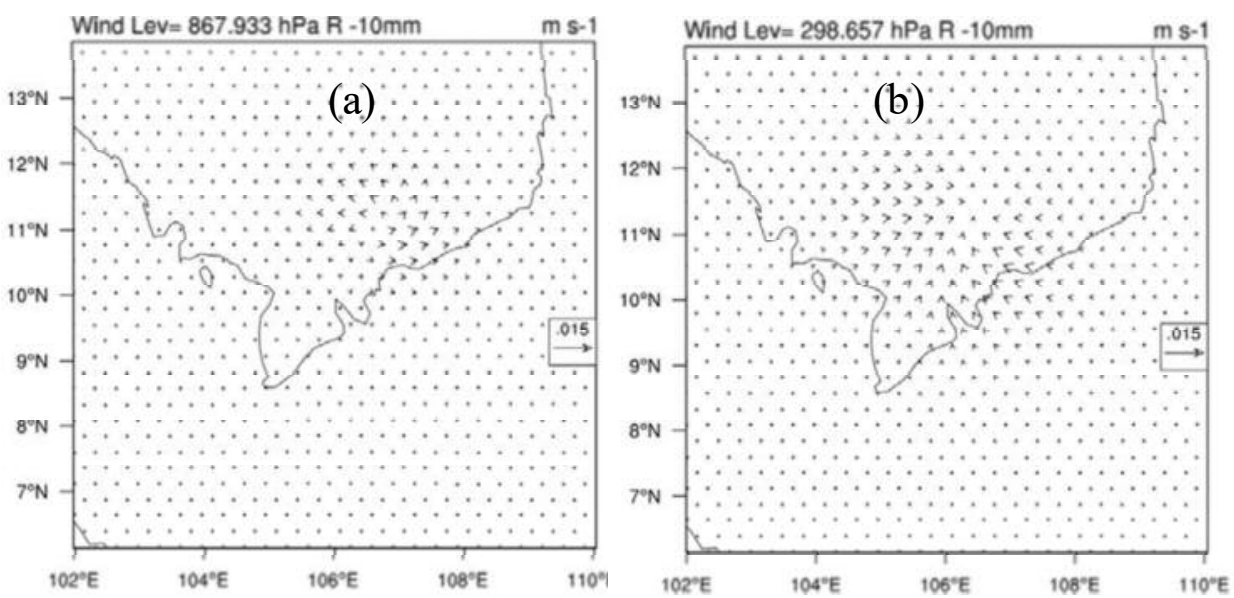

Hình 10. Hiệu trương gió của truờng phân tích trù̀ đi truờng ban đầu ở mục 850 hPa (a) và mục $\sim 300 \mathrm{hPa}$ (b) trong thí nghiệm TN2 


\subsection{Dụ báo đọt mura 25-26/11/2018}

Hình 11 so sánh kết quả mô phỏng lượng mưa tích lũy 24h ngày 25/11/2018 từ các thí nghiệm, so sánh với số liệu quan trắc. Số liệu quan trắc cho thấy các tỉnh Bến Tre, Trà Vinh, Vĩnh Long, Long An, Tây Ninh, Bình Dương xảy ra mưa lớn với lượng mưa phổ biến trong khoảng 20100mm (Hình 11.a). Tại khu vực TP. Hồ Chí Minh, xuất hiện một tâm mưa lớn với lượng mưa 200-300mm và tại Bà Rịa Vũng Tàu, xảy ra mưa rất lớn (trên $500 \mathrm{~mm}$ ).

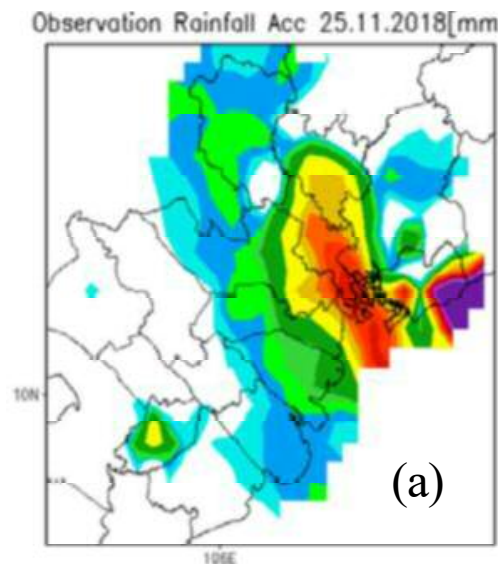

[30_RADAR] Acc Roin At 12225NOV

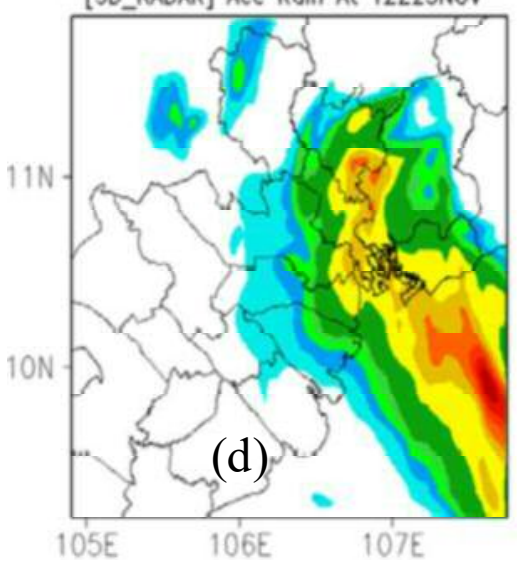

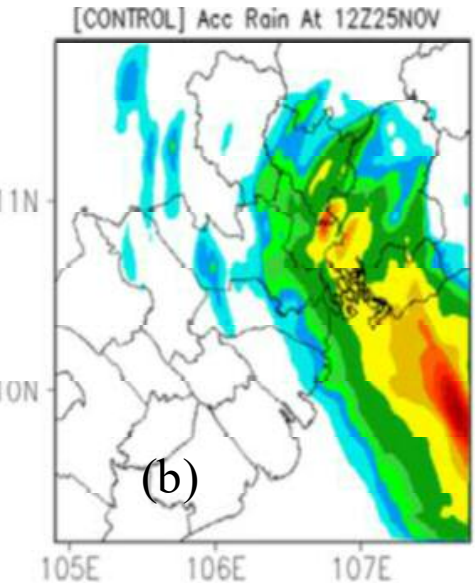

[40 RAINRADAR] ACC Roin At 12225NOV

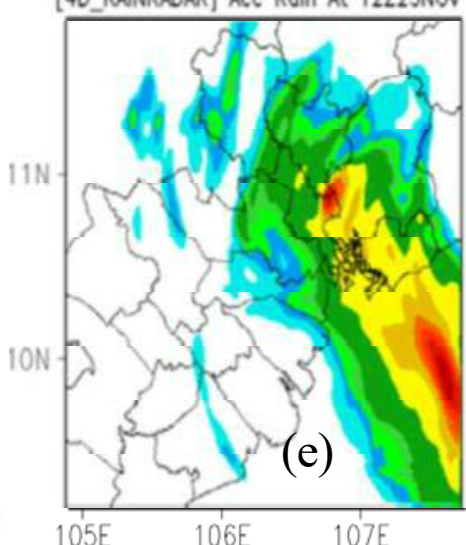

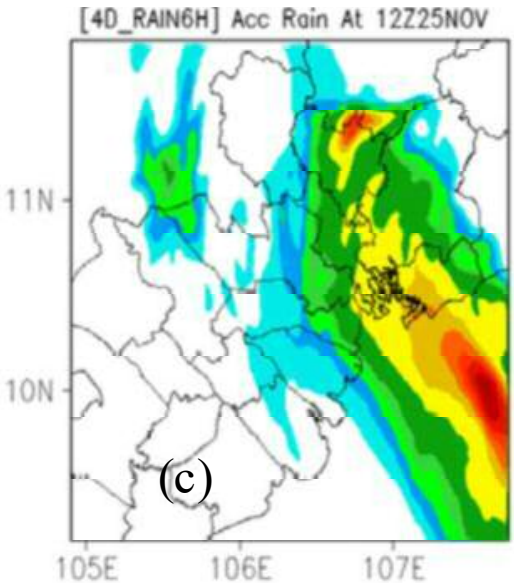

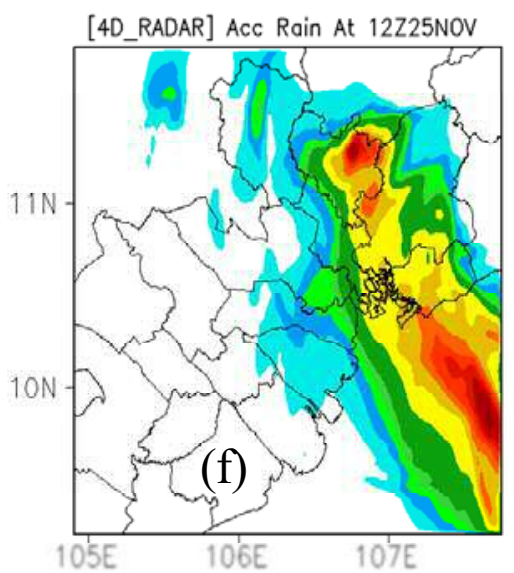

Hình 11. Lương mura tích lũy 24h ngày 25/11/2018 của quan trắc (a), CTL (b), 4D_RAIN6H (c), 3D_RADAR (d), 4D_RAINRADAR (e), 4D_RADAR (f)

Với các thí nghiệm của WRF, trường hợp CTL (Hình 11.b) cho thấy mô hình nắm bắt chưa tốt tâm mưa tại TP.Hồ Chí Minh. Tâm mưa bị lệch về phía đông, lượng mưa tại các khu vực thấp hơn khá nhiều so với quan trắc. Trong khi đó, trường hợp đồng hóa 3D-Var sử dụng số liệu radar đã giúp mô hình mô phỏng khá tốt tâm mưa tại TP.Hồ Chí Minh, tuy lượng mưa cũng thấp hơn so với thực tế (Hình 11.d). Ở các trường hợp đồng hóa 4D-Var, có thể thấy mô hình vẫn chưa mô phỏng đúng tâm mưa ở TP. Hồ Chí Minh. Trong đó, trường hợp đồng hóa 4D-Var với số liệu mưa và cửa sổ đồng hóa $6 \mathrm{~h}$ (Hình 11.c) và với số liệu radar (Hình 11.f) mô phỏng lượng mưa cao hơn nhiều so với thực tế ở phía bắc tỉnh Bình Dương. Trường hợp đồng hóa 4DVar sử dụng cả số liệu mưa và radar (Hình 11.e) mô phỏng diện mưa khá giống CTL nhưng lượng mưa có phần tốt hơn, khi so với quan trắc. Tất cả các thí nghiệm đều không bắt được tâm mưa rất lớn tại Bà Rịa Vũng Tàu.

Ngày 26/11/2018, sau khi bão đã tan, số liệu quan trắc cho thấy lượng mưa giảm đi đáng kể và chỉ xảy ra mưa lớn cục bộ ở một vài nơi trong tỉnh Tây Ninh, TP. Hồ Chí Minh, Long An, với 


\section{BÀI BÁO KHOA HỌC}

lượng mưa khoảng 300mm (Hình 12a). Các kết còn đối với các điểm mưa lớn cục bộ gần như quả mô phỏng chỉ bắt được diện mưa ở khu vực, không nắm bắt được.
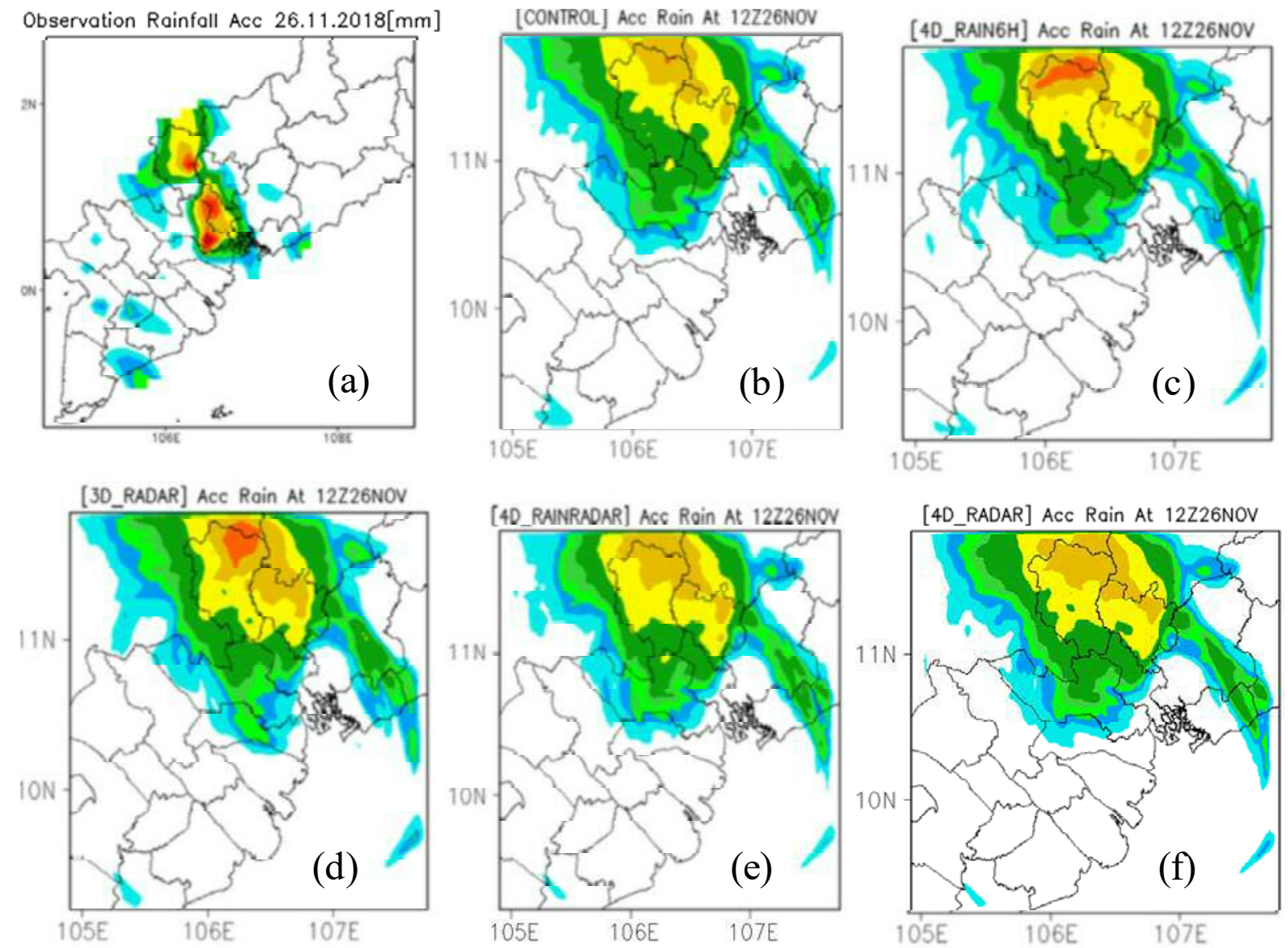

Hình 12. Lượng mưa tích lũy 24h ngày 26/11/2018 của quan trắc (a), CTL (b), 4D_RAIN6H (c), 3D_RADAR (d), 4D_RAINRADAR (e), 4D_RADAR (f)

Kết quả đánh giá kỹ năng dự báo ở hạn $12 \mathrm{~h}$ cho thấy, ở các ngưỡng mưa nhỏ (1 - 30mm) phương án 3D_RADAR, 4D_RADAR, 4D_RAIN6H cho kết quả có cải thiện so với CTL (Hình 13). Tuy nhiên, với ngưỡng mưa vừa đến mưa lớn (40 - 70mm), giá trị của các chỉ số của phương án CTL lại tốt hơn số với các trường hợp khác. Ở các ngưỡng cao hơn thì các phương án đồng hóa cho kết quả tốt hơn so với CTL. So sánh giữa các phương án đồng hóa, ở hạn 12h, cho thấy 3D_RADAR có sai số nhỏ hơn cả. Bên cạnh đó, 4D_RADAR cho kết quả chỉ số tốt hơn 4D_RAIN6H và 4D_RAINRADAR. Ở hạn dự báo 24h (Hình 14), các thí nghiệm 3D_RADAR, 4D_RAIN6H, 4D_RAINRADAR cải thiện khá tốt chỉ số FBI ở các ngưỡng mưa. Riêng thí nghiệm 4D_RADAR cho kết quả kém hơn CTL ở ngưỡng mưa $20-50 \mathrm{~mm}$.

\section{Kết luận}

Các kết quả thử nghiệm bước đầu về việc ứng dụng phương pháp đồng hóa số liệu biến phân bốn chiều (4D-Var) trong mô hình WRF đã được trình bày trong nghiên cứu này. Số liệu được đồng hóa bao gồm số liệu radar và số liệu quan trắc mưa tự động. Hai loạt thí nghiệm đã được tiến hành bao gồm (1) thử nghiệm với một quan trắc đơn nhằm đánh giá độ nhạy và tác động của đồng hóa 4D-Var và (2) thử nghiệm đồng hóa số liệu trong một trường hợp thực tế với 5 thí nghiệm được xây dựng (CTL, 4D_RAIN6H, 4D_RADAR,4D-RAINRADAR, 3D_RADAR). Kết quả của thử nghiệm với quan trắc đơn cho 
thấy phương pháp 4D-Var đã điều chỉnh các biến cơ bản của trường ban đầu như biến nhiệt độ, độ ẩm hay trường gió kinh vĩ hướng khi lượng mưa được đồng hóa thay đổi. Phương pháp 4D-Var cho thấy độ nhạy với các trường này dù chỉ có sự thay đổi nhỏ từ số liệu quan trắc được đồng hóa. Kết quả mô phỏng thực tế cho đợt mưa ngày 25 và $26 / 11 / 2018$ cho thấy, so với trường hợp không đồng hóa (CTL), phương pháp đồng hóa 4D-Var đã có tác động cải thiện dự báo ở cả hạn dự báo $12 \mathrm{~h}$ và $24 \mathrm{~h}$. Ở hạn dự báo $12 \mathrm{~h}$, các phương án đồng hóa nhìn chung có sai số nhỏ hơn so với CTL, ở các ngưỡng mưa nhỏ và mưa lớn (1 - 30mm và trên $70 \mathrm{~mm})$. Ở hạn dự báo $24 \mathrm{~h}$, đồng hóa số liệu giúp cải thiện đối với chỉ số FBI. Tuy nhiên, nghiên cứu cũng chỉ ra yêu cầu về mặt tài nguyên tính toán của phương pháp 4D-Var lớn hơn đáng kể so với phương pháp $3 \mathrm{D}-$ Var. Đây là những kết quả đầu tiên của việc ứng dụng phương pháp 4D-Var tại Việt Nam (theo tìm hiểu của nhóm nghiên cứu) và đã mở ra những triển vọng cũng như lưu ý cho việc khai thác phương pháp này trong tương lai ở Việt Nam.

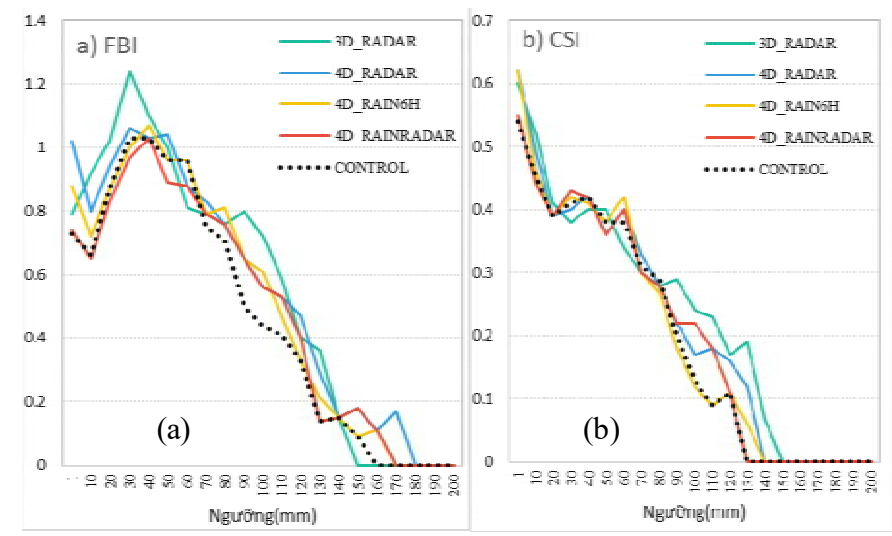

Hình 13. Chỉ số FBI (a) và CSI (b) ở hạn dụ báo 12 hới các ngương mưa tù 1 đến $200 m m$ của các trương hợp thử nghiệm

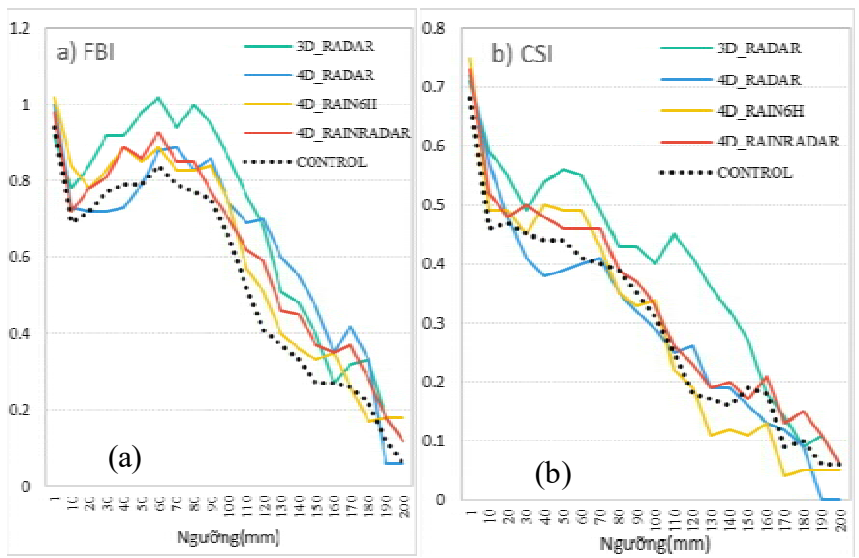

Hình 14. Chỉ số FBI (a) và CSI (b) ở hạn dụ báo 24 hới các ngữong mưa tù 1 đến $200 m m$ của các trưòng hợp thử nghiệm 


\section{BÀI BÁO KHOA HỌC}

Lời cảm ơn: Bài báo là một phần kết quả nghiên cứu của Đề tài "Nghiên cưu xây dụng hệ thống nghiệp vu dụ báo định lương mua khu vục Nam Bộ và cảnh báo mura lớn hạn cực ngắn cho thành phố Hồ Chí Minh", mã số KC.08.14/16-20.

\section{Tài liệu tham khảo}

1. Barker, D., Huang, X.Y., Liu, Z., Auligné, T., Zhang, X., Rugg, S., Demirtas, M., (2012), The weather research and forecasting model's community variational/ensemble data assimilation system: WRFDA. Bulletin of the American Meteorological Society, 93 (6), 831-843.

2. Gauthier, P., Tanguay, M., Laroche, S., Pellerin, S., Morneau, J., (2007), Extension of 3DVAR to 4DVAR: Implementation of $4 D V A R$ at the Meteorological Service of Canada. Monthly weather review, 135 (6), 2339-2354.

3. Huang, X.Y., Xiao, Q., Barker, D.M., Zhang, X., Michalakes, J., Huang, W., ... Dudhia, J., (2009), Four-dimensional variational data assimilation for WRF: Formulation and preliminary results. Monthly Weather Review, 137 (1), 299-314.

4. Huỳnh Thị Hồng Ngự, La Thị Cang (2008), Đồng hóa số liệu bằng phưong pháp biến phân bốn chiều trong dự báo thời tiết bằng phuơng pháp số trị. Tạp chí Phát triển KHCN, 11 (12), 98103.

5. Ban, J., Liu, Z., Zhang, X., Huang, X.Y., Wang, H., (2017), Precipitation data assimilation in WRFDA 4D-Var: implementation and application to convectionpermitting forecasts over United States. Tellus A: Dynamic Meteorology and Oceanography, 69 (1), 1368310, DOI: $10.1080 / 16000870.2017 .1368310$

6. Kumar, P., Kishtawal, C.M., Pal, P.K., (2014), Impact of satellite rainfall assimilation on Weather Research and Forecasting model predictions over the Indian region. Journal of Geophysical Research: Atmospheres, 119 (5), 2017-2031.

7. Lê Đức, Đỗ Lệ Thủy, Lương Hồng Trung (2007), Xây dựng trường ẩm cho mô hình HRM tù số liệu vệ tinh địa tĩnh dựa trên phuơng pháp biến phân ba chiều (3D-Var) (Phần I: cơ sở khoa học và phưong pháp thực hiện). Tạp chí Khí tượng Thủy văn, 555, 22-32.

8. Lê Đức, Đỗ Lệ Thủy, Lương Hồng Trung (2007), Xây dựng trường ẩm cho mô hình HRM tù số liệu vệ tinh địa tĩnh dựa trên phưong pháp biến phân ba chiều (3D-Var) (Phần II: phuơng pháp thực hiện và một số kết quả nghiên cưu). Tạp chí Khí tượng Thủy văn, 558, 43-49.

9. Lopez, P., Bauer, P., (2007), '1D+4D-Var'assimilation of NCEP stage IV radar and gauge precipitation data at ECMWF. Monthly Weather Review, 135, 2506-2524.

10. Lopez, P., (2011), Direct 4D-Var assimilation of NCEP stage IV radar and gauge precipitation data at ECMWF. Monthly Weather Review, 139, 2098-2116.

11. Mazzarella, V., Maiello, I., Capozzi, V., Budillon, G., Ferretti, R., (2017), Comparison between 3D-Var and 4D-Var data assimilation methods for the simulation of a heavy rainfall case in central Italy. Advances in Science and Research, 14, 271.

12. Pan, X., Li, X., Cheng, G., Hong, Y., (2017), Effects of 4D-Var data assimilation using remote sensing precipitation products in a WRF model over the complex terrain of an arid region river basin. Remote Sensing, 9 (9), 963.

13. Rabier, F., J"arvien, H., Mahfouf, J.F., Simmons, A., (2000), The ECMWF operational implementation of four-dimensional variational assimilation: Experimental results with simplified physics. Quarterly Journal of the Royal Meteorological Society, 126, 1148-1170.

14. Skamarock, W.C., Klemp, J.B., Dudhia, J., Gill, D.O., Barker, D.M., Duda, M.G., Huang, 
X.Y., Wang, W., Powers, J.G., (2008), A description of the Advanced Research WRF v3. NCAR Technical Note NCAR/TN-475CSTR.

15. Trần Duy Thức, Công Thanh (2018), Thử nghiệm đồng hóa dũ liệu radar trong mô hình WRF để dư báo mue lón cho khu vực Thành phố Hồ Chí Minh. Tạp chí Khoa học ĐHQGHN: Các Khoa học Trái đất và Môi trường, 34 (1S), 59-70.

\section{DATA ASSIMILATION WITH WRF 4D-VAR FOR RAINFALL FORECASTING OVER THE SOUTH OF VIETNAM Thang Vu Van', Thuc Tran Duy ${ }^{1}$, Trung Nguyen Quang ${ }^{1}$}

${ }^{1}$ Vietnam Institute of Meteorology, Hydrology and Climate Change

Abstract: Four-Dimensional Variational data assimilation (4D-Var) is an innovative technique applying in many weather forecasting centers over the world, due to its advantages of using observations at the time of their measurement or in predetermined time bins and using a forecast model to enhance the dynamic balance of the final analysis. This study, for the first time in Vietnam, presents an attempt to apply Weather Research and Forecasting model (WRF) with 4D-Var for rainfall forecasting over the South of Vietnam. Data from 219 rain gauges and a weather radar are used to assimilated for the heavy rainfall event of 25 and 26 November 2018. In addition, single observation tests are also carried out to evaluate the sensitivity of WRF 4D-Var to the variation of observed rainfall. The results show that WRF 4D-Var modified meteorological variables of the first guess (e.g. temperature, humidity) even with a small change of assimilated rainfall amount. Experiments in the realistic case highlight that WRF $4 D$-Var can slightly improve rainfall forecast results, in comparison with non-data assimilated case, at lead-times of 12 hours and 24 hours. In general, data assimilation contributes to the decrease of forecast bias at rainfall threshold below $30 \mathrm{~mm}$ and above $70 \mathrm{~mm}$. This study also emphasizes the significant requirement of computing resource when applying the $4 D$-Var technique.

Keywords: WRFDA, 4DVar, Data assimilation, Radar, Heavy rainfall, The South of Vietnam. 